\title{
خصائص فريق التصميم وأثرها على تصميم المباني الخضراء في ليبيا
}

\author{
محمد الصغير الفرجاني، عبد الباسط محمد الفيتوري2 \\ 1 أستاذ مساعد بقسم العمارة والتخطيط العمراني - كلية الهندسة - القره بوللي - جامعة المرقب \\ 2 عضو هيئة تدريس بقسم العمارة والتخطيط العمراني - كلية الهندسة - طرابلس - جامعة طرابلس \\ 1email: mselforgani@elemrgib.edu.ly \\ 2email: amfeturi@gmail.com
}

الملخص

استدامة البيئة العمرانية تلعب دوراً مهمّا في تحقيق الاستدامة بشكل عام، وتعدّ مرحلة التصميم هي أهم مراحل المشروع، وفريق التصميم اللاعب الرئيس في هذه المرحلة، وتكمن مشكلة البحث في تدني مستوى مخرجات تصميم المباني الخضراء في ليبيا، كما يهدف البحث إلى دراسة خصائص فريق التصميم وأثرها على مستوى مخرجات تصميم المباني الخضراء في ليبيا، ومن خلالها تحديد مستوى أداء فريق التصميم والصعوبات التي تواجهه أثناء عمليات تصميم المباني الخضراء. اتبّعت الدراسة منهجية التثليث في البحث؛ حيث بدأت بالدراسات السابقة، ثمّ مرحلة تجميع البيانات باستخدام الاستبيان ث إجراء المقابلات الشخصية لتأكيد النتائج وتعميق الاستنتاجات. أستُخدم برنامج SPSS للمباني الخضراء. كما أظهرت نتائج الدراسة مستوى متوسط للخصائص العامة، وتدني كبير في الخصائص الخضراء. كما استُنتج الصعوبات التي تواجه فريق التصميم عند تصميم المباني الخضراء في ليبيا، وخُتمت الدراسة ببعض التوصيات التي من شأنها تحسّن أداء فريق التصميم. الكلمات الافتتاحية: المباني الخضراء، التصميم الأخضر، التصميم المستدام، فريق التصميم، خصائص الفريق.

المقدمة

تهتم الدول المتقدمة وكثيرٌ من الدول النامية بتحقيق متطلبات الاستدامة في البيئة العمرانية لما لها من آثار سلبيّة عند إهمال الاهتمام بها؛ فالبيئة المشيّدة تساهم إسهاماً فعّالاً في حجم انبعاثات غاز CO2 واستنزاف الموارد والثلوث البيئي للمياه والهواء؛ لذلك كان لزاماً تتبّع المشاريع الإنشائية والاهتمام بتحقيق الاستدامة في كل مراحلها، وتعدّ مرحلة التصميم أهم هذه المراحل لتفردها بغالبية القرارات التصميمية التي تخص المبنى مثل اختيار الموقع، والتّوجيه، والثّكل المعماري والمواد المستعملة 
وغيرها، وخلال هذه المرحلة يكون دور فريق التصميم من أهم الأدوار بين الأطراف المنخرطة في

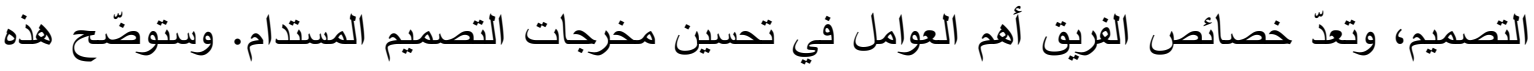
الورقة البحثية الاهتمام بخصائص فريق التصميم ودورها في تحسين مخرجات تصميم المباني الخضراء بليبيا. المثكلة البحثية

تساهم البيئة المشيّة بقدر لا يمكن تجاهل تأثيره السلبي على البيئة نتيجة لما تتنجه من انبعاثات لغاز

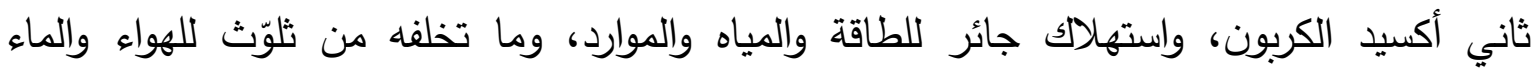

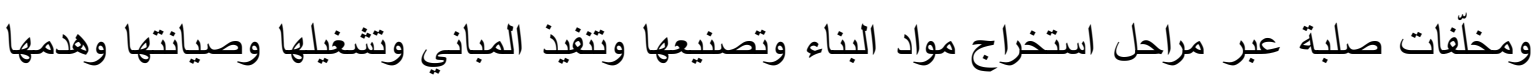

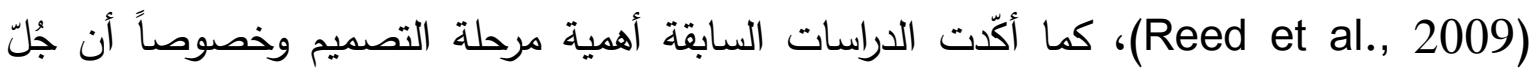
القرارات التي تعكس سلوك المبنى يتم اتخاذها في هذه المرحلة (Harputlugil, 2009)، وخلال

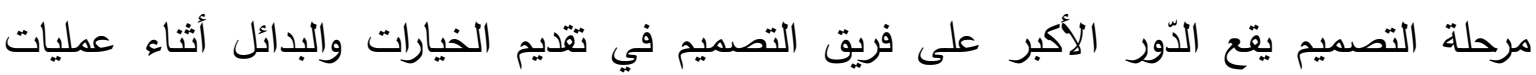

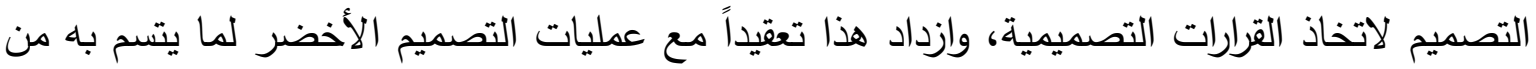

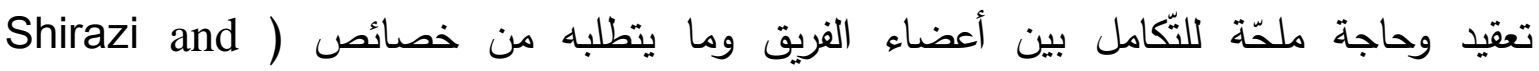
Mortazavi, 2009 وبما أنّ مستوى استدامة المباني في أغلب دول العالم المتقدّم متدنٍ فإنّ البيئة

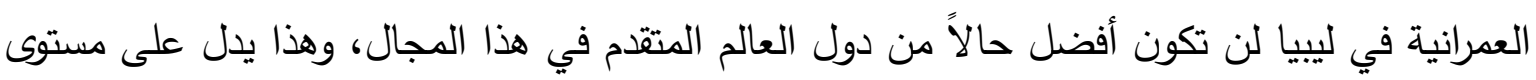
مخرجات تصميم غير مستدامة وجاء نتاج عمل فريق تصميم قد لا يمتلك خصائص فئ تؤهّله لإنتاج

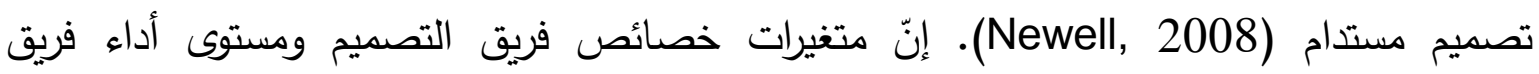

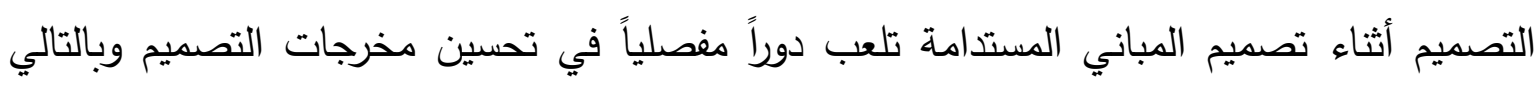
تحسين كفاءة المباني الخضراء؛ فمشكلة البحث تتلخص في ماهيّة خصائص فريق لفئ التصميم التي تمكنه من تصميم بيئة عمرانية خضراء.

الإطار النظري وتساؤلات البحث

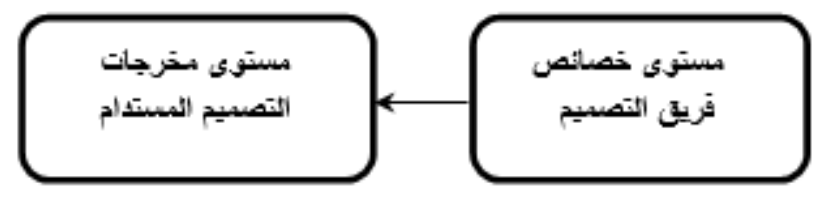

الثكل (1): الإطار النظري للبحث 
تساؤلات البحث: يتمّ في هذا البحث دراسة متغيّرات عامل مستوى خصائص فريق التصميم وأثرها على العى متغيّرات العامل المستقل، ومستوى مخرجات التصميم المستدام، ويمكن تلخيص تساؤلات البحث التي لتئي سوف يتم اختبارها على النحو التالي:

1. هل مستوى مخرجات التصميم المستدام يتأثر بمستوى جودة خصائص فريق التصميم؟

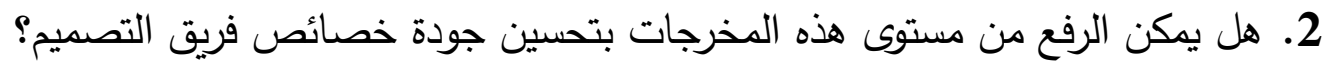

أهداف البحث

يهدف البحث إلى معرفة سبل تحسين مخرجات التصميم المستدام؛ عليه يمكن تحديد أهدافه في:

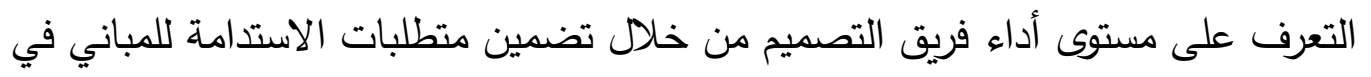
ليبيا.

هالتعرف على خصائص فريق التصميم العامة والخصائص التي لها علاقة بالتصميم المستدام.

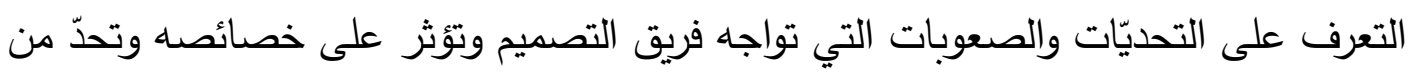
الرفع بمستوى مخرجات التصميم المستدام.

مجال الدراسة وحدودها

تركّز الدراسة بشكل عام على تحسين مستوى تصميم البناء المستدام وعلى خصائص فريق التصميم على وجه الخصوص لأهميته وأثثر على مستوى مخرجات التصميم المستدام، وسيكون مجال الدراسة

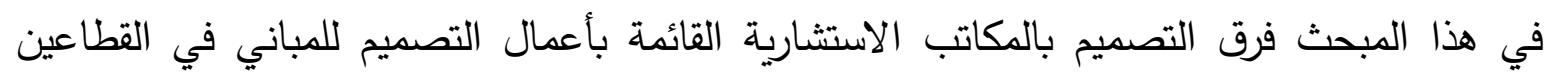

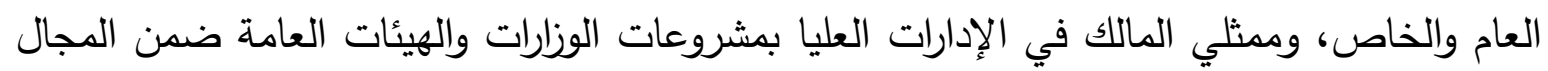
الجغرافي لليبيا.

الارراسات السابقة

مخرجات المباني في ليبيا

بلغت الآثار السلبية للبيئة المشيّة مداها على عالمنا اليوم؛ حيث أوضحت الدراسات السابقة أن البيئة

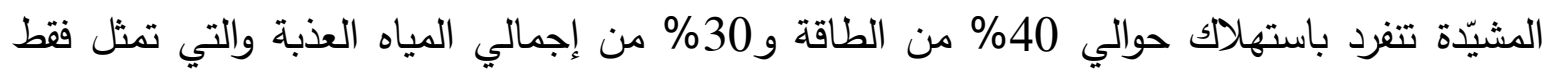

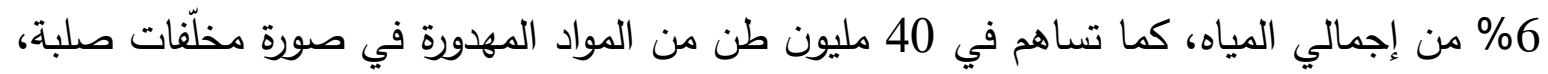

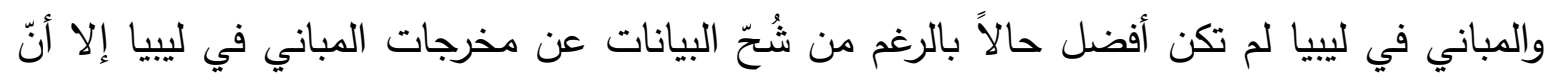

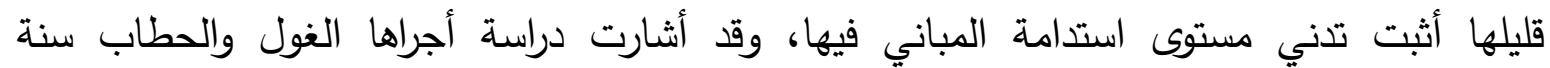
(2016) إلى تدني مستوى استدامة المباني في ليبيا؛ فمثلاً المباني السكنية وحدها في ليبيا تستهلك حوالي 36 \% من الطاقة (Ekhlat et al., 2007). 
الدراسات السابقة أثبتت أهمية مرحلة التصميم في تحسين مستوى استدامة المباني باعتبار أن 80 \%

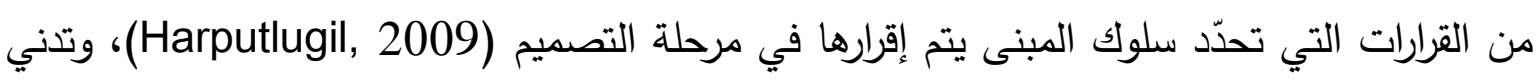

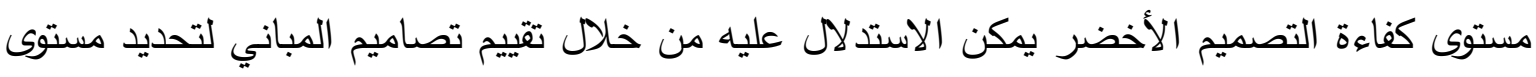
تضمين متطلبات الاستدامة في مرحلة التصميم. مستوى مخرجات التصميم الأخضر في ليبيا كان الاندان

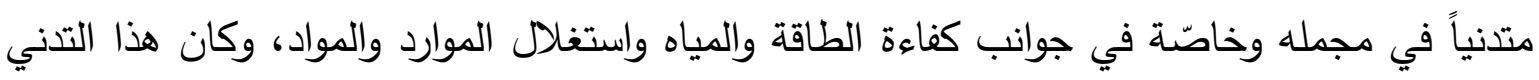

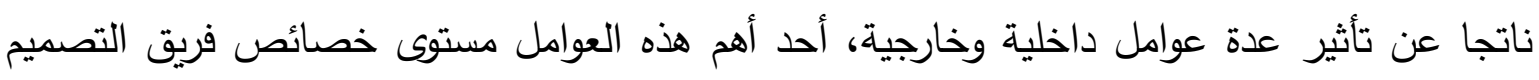

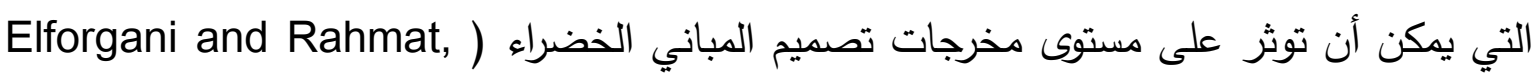
.2010

خصائص فريق التصميم

كلّما زاد حجم المشروع وازداد تضمين الخدمات الهندسية في المباني ازدادت عمليات التصميم للمباني

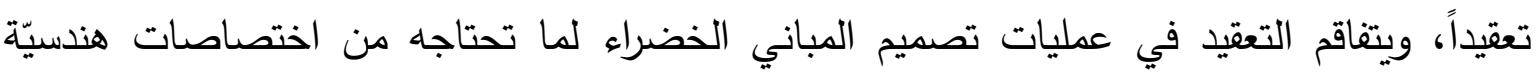

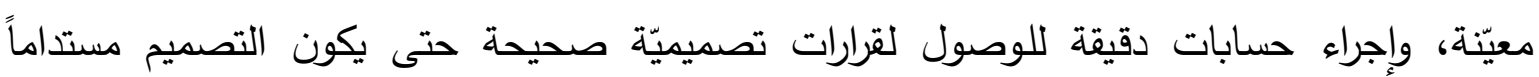

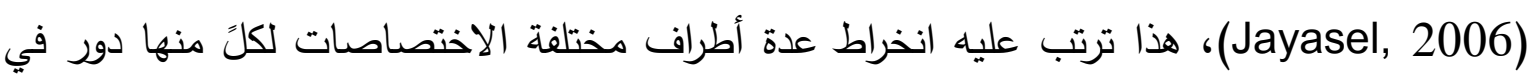
العملية التصميمية؛ لذلك يري (Forgues and Lauri, 2008) ضرورة الاهتمام بخصائص وجودة التهات الفريق الذي سيتم تكوينه لما لها من أثر على مستوى مخرجات التصميم وهذا ما أظهره تقرير مجلس

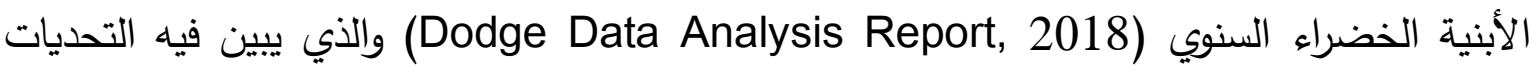

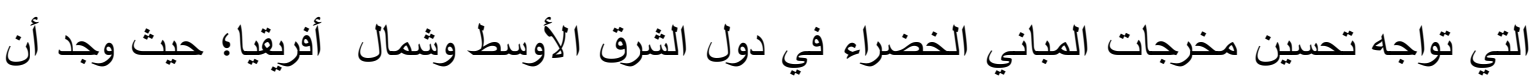
كفاءة فريق التصميم تساهم بحوالي 28\% من تحسين مجمل العوائق التي تواجه تحسين مخرجات المباني

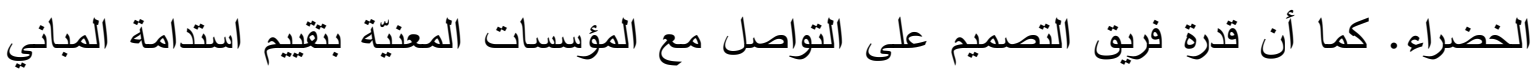

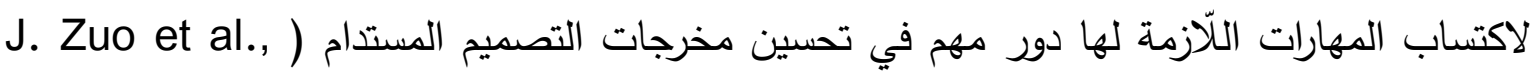
. (2016

تناولت الدراسات السابقة خصائص فريق التصميم التي من شأنها تحسين أداء فريق التصميم بشكل

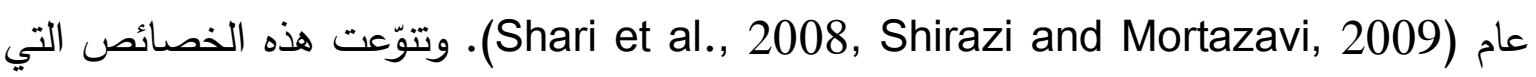

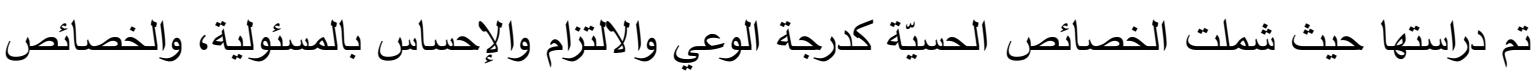
الملموسة كمهارات التصميم ومهارات استخدام التقنيات والقدرات العملية كالإدارة والتتظيم والقيادة.

هناك عدة خصائص لفريق التصميم من شأنها تحسين مخرجاته تم تتاولها، ولمحدودية الدراسة

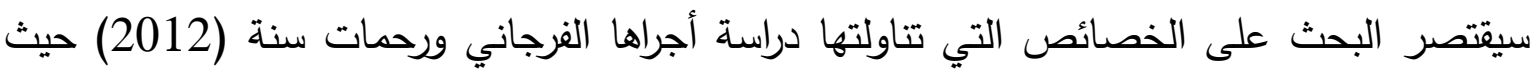

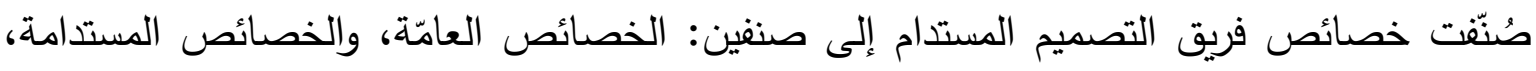


وشملت سبع متغيّرات تمثلت في: الخبرة المتعلقة بالتصميم المستدام، والمعرفة بالتصميم المستدام، والمهارات، وإدارة عمليات التصميم، وفاعلية التواصل، والقدرة على إنجاز الأعمال، ودرجة التزام الفريق بتضمين متطلبات المباني الخضراء. واتهات

إنّ عدم المعرفة الكافية لدى فريق التصميم بمتطلبات التصميم المستدام أحد العوائق التي تحد من مستوى مخرجات التصميم المستدام، هذه الخاصية ذكرها غرهام سنة (2003) حيث أشار إلى أهمية

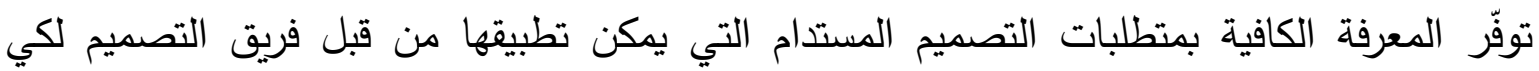

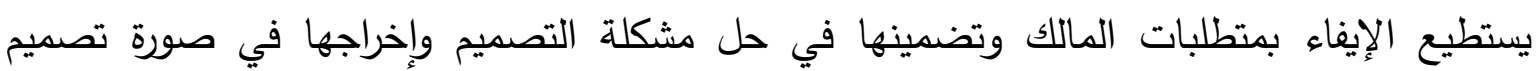

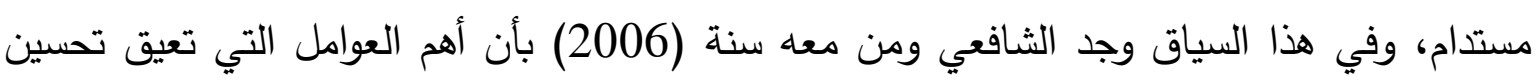

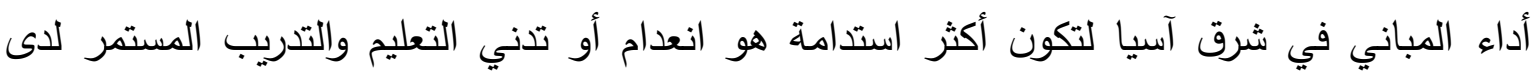
فريق التصميم بشأن مفاهيم ومتطلبات وآليات البناء المستدام.

إن ترجمة المعرفة إلى تطبيق خلال عمليات تصميم المباني الخضراء يحتاج إلى مهارات لاى أعضاء

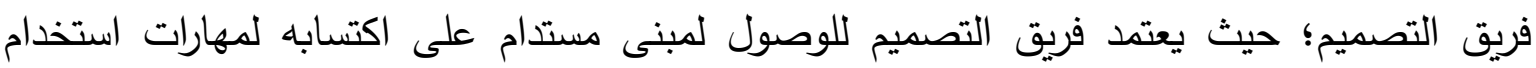

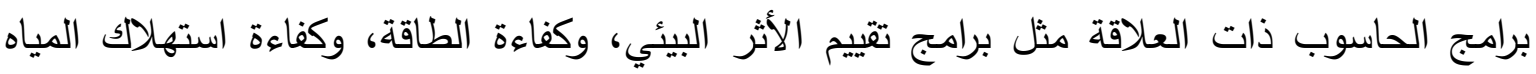

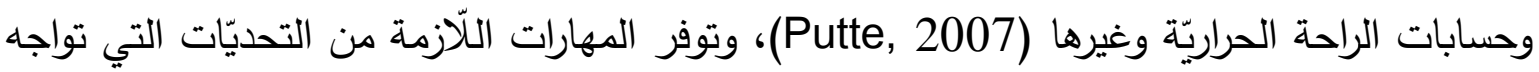
فريق التصميم للوصول لتصميم مباني خضراء (Megat, 2006).

يعتمد نجاح فريق التصميم في إنجاز مهامه على فاعلية إدارة عمليات التصميم؛ حيث يعتبر نيوتن

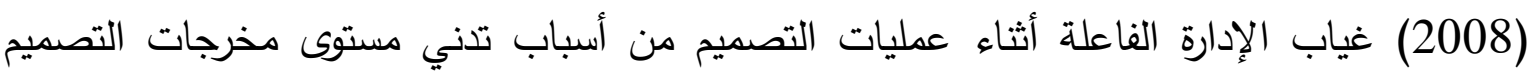

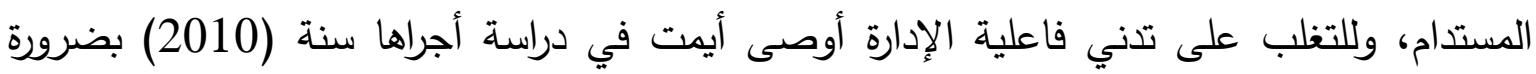

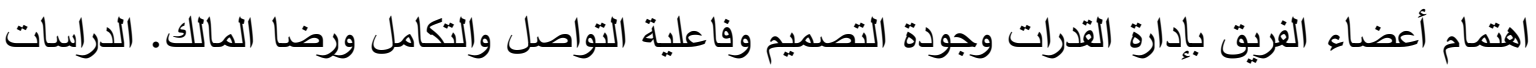

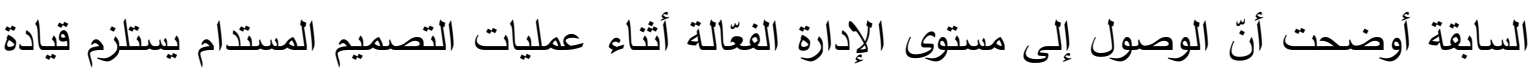

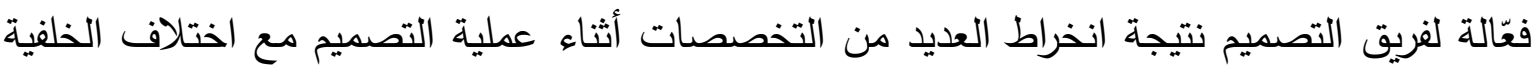
العلمية والعملية وما يترتب عليه من إسناد للمهام ومتابعتها، واتخاذ القرارات التصميمية يتطلب قيادة

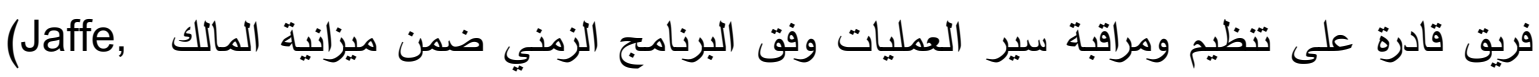

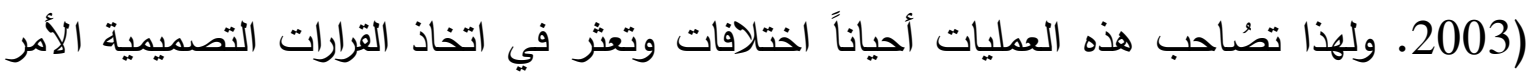

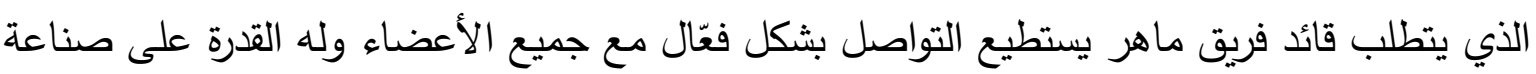
القرار واتخاذه في وقته (Gilley et al, 2010).

كما أن التكامل بين أعضاء فريق التصميم أثناء مراحل التصميم المختلفة يعتبر أهم تحدٍ يواجه فريق تصميم أثناء عمليات تصميم المباني المستدامة؛ حيث وجد دنيال سنة (2007) أن تحقيق التكامل 
بين أعضاء الفريق والأطراف المنخرطة في عمليات التصميم والتواصل الفعال والتتسيق فيما بينهم من

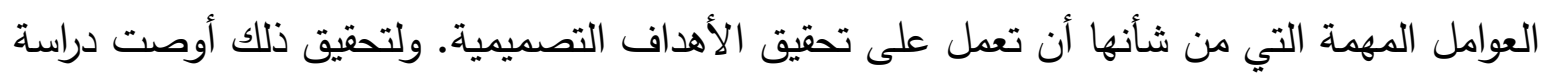

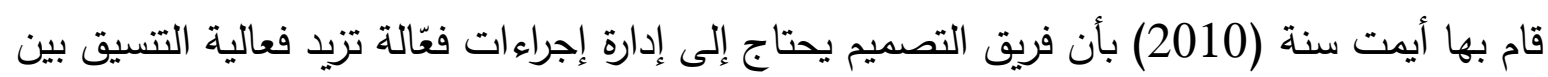
أعضاء الفريق أثناء عمليات التصميم.

إنّ الاقتناع التام بأهمية تحقيق الاستدامة والإحساس بالمسؤولية اتجاهها للى أعضاء فريق التصميم يعتبر عاملاً مؤثراً في مستوى أداء فريق التصميم نحو تضمين متطلبات الاستدامة. هذا ما أكدته

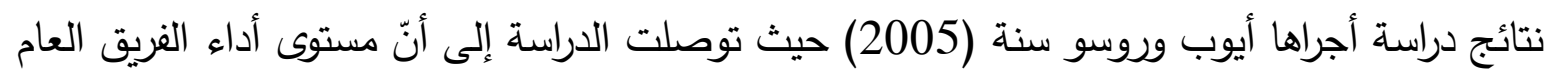

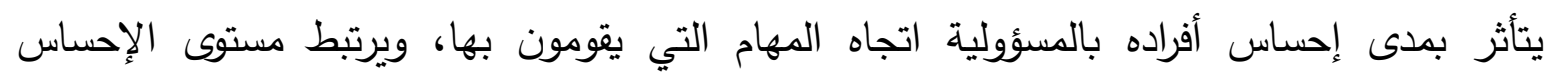

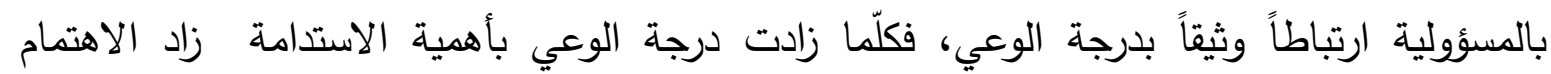

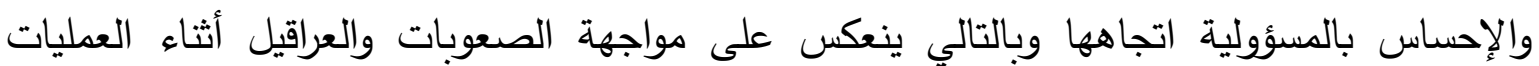
التصميمية، وعند اتخاذ القرارات التصميمية بمخرجات التصميم المستدام (Lantz and Kin, 2009). ممّا سبق يتضح أنّ لخصائص فريق التصميم معظم الأثر على مستوى مخرجات التصميم وقد تتفاوت لتصني أهمية هذه الخصائص وأثرها على مخرجات التصديم الدستدام.

\section{منهجية البحث}

يتناول هذا البحث مستوى كفاءة وتأثير خصائص فريق التصميم كأحد العوامل المؤثرة في مستوى مخرجات التصميم المستدام للعمارة والعمران، وقد تم تأطير الإطار النظري بالتأكيد لتصني على العامل

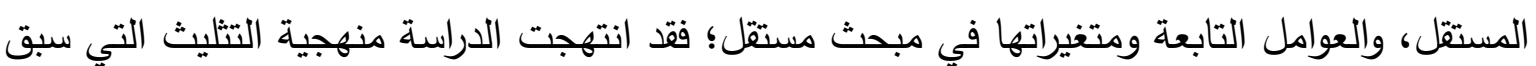

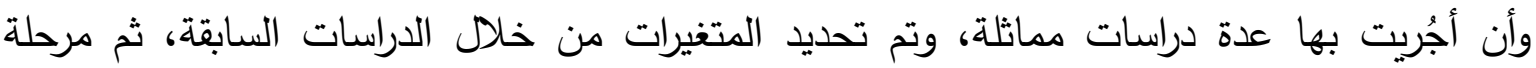

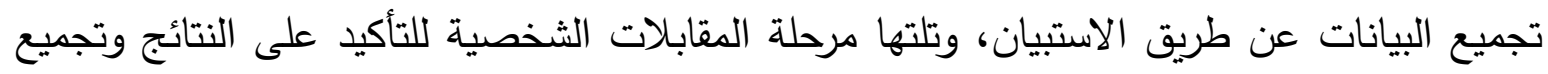

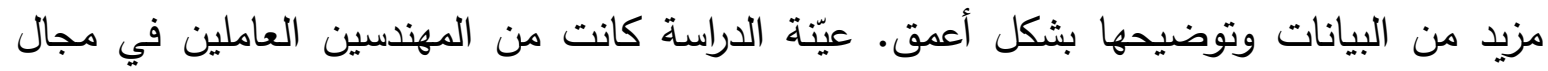

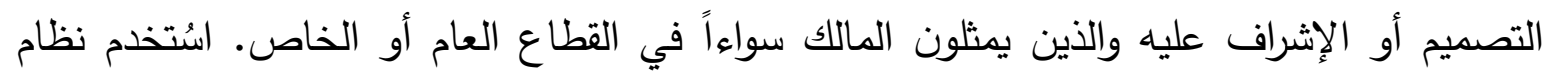
تقييم المباني الخضراء (Green Building Index GBI) لتقييم مستويات الأداء لكافة متطلبات الاستدامة في التصميم. كما اسُتخدم برنامج SPSS الإحصائي لتحليل النتائج؛ حيث استخدم الأبئ الإحصاء الوصفي والاستدلالي لتحليل عيّة الدراسة للاستدلال عن معالم مجتمع الدراسة بناء على لئى

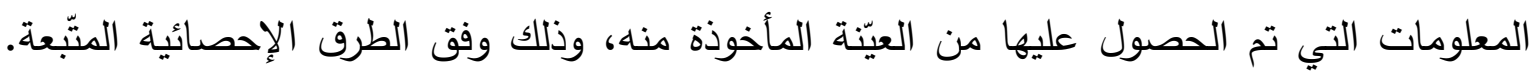
معامل الثبات (Alpha Cronbach) قيمته 0.858 ومعامل صدق العيّنة 0.926 ممّا يؤكد بأن العيّنة تتمتع بمصداقية ويمكن الاعتماد عليها. 
تم تصنيف عرض ومناقثة النتائج حسب الإطار النظري للدراسة؛ لذلك سوف يتم استعراض ومناقشة

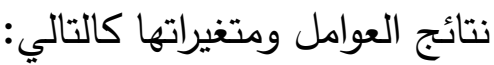

\section{مستوي خصائص فريق التصميم}

تناول البحث تقييم مستوى أداء الفريق من خلال تقييم سبع متغيرات أساسية ثلاث منها خصائص

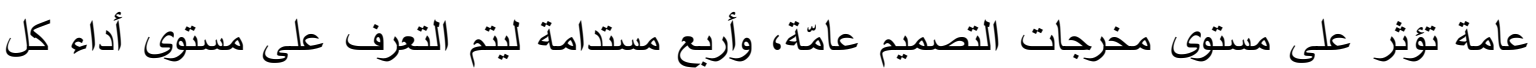

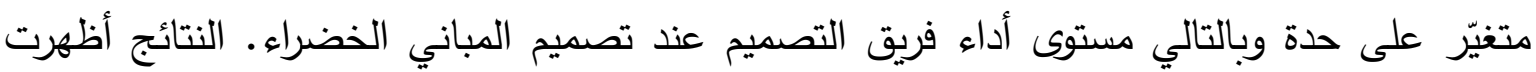
كما بالجدول رقم (1) أن مستوى أداء فريق التصميم كان متدنياً حيث سجلت التئ النتائج (2.58) فقط، والجدير بالملاحظة هنا أن الخصائص العامة والمتعلقة بالتصميم بشكل عام كان مستوى أداء فريق

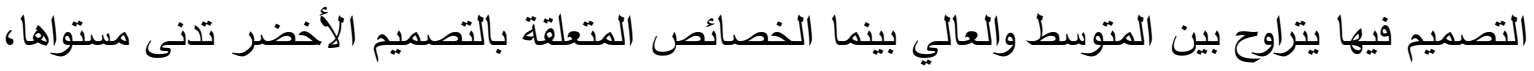

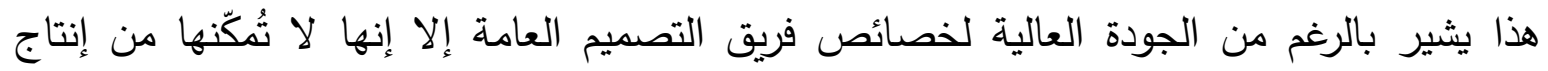
تصاميم خضراء للمباني وذلك لقصور في مستوى خصائصها الخضراء.

الجدول (1): مستوى خصائص فريق التصميم عند تصميم المباني الخضراء

\begin{tabular}{|c|c|c|c|}
\hline التصميم المستدام & الوسيط & متغيرات خصائص الفريق & تصنيف \\
\hline متدنٍ & 2.55 & الخبرة في مجال التصميم & \multirow{3}{*}{ خصائص } \\
\hline عالٍ & 3.26 & فاعلية إدارة عمليات التصميخ & \\
\hline عالٍ & 3.03 & فاعلية التواصل وإدارة المهام & \\
\hline 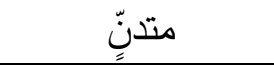 & 1.91 & مستوى المعرفة بالتصميم المستدام & \multirow{4}{*}{ الاستدامة } \\
\hline متدنّ جدا & 1.69 & مستوى مهارات التصميم المستدام & \\
\hline متوسط & 2.83 & 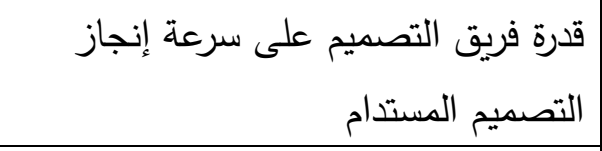 & \\
\hline 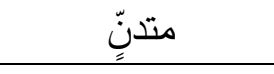 & 2.22 & درجة التزام الفزيق نحو التصميم المستدام & \\
\hline 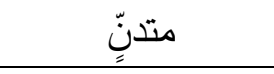 & 2.58 & \multicolumn{2}{|l|}{ المعدل العام لخصائص فريق التصميم } \\
\hline
\end{tabular}

من خلال ذلك يتبيّن أن أغلب فرق التصميم عند انخراطها في أعمال تصميم المباني الخضراء لا تثتر إلى الخصائص العامة مثل المعرفة والخبرة وإدارة عمليات التصميم وإنما تفتقر إلى المعرفة والدراية والمهارات الكافية لتضمين متطلبات الاستدامة. وهذا يشير إلى أن فرق تصميم المباني الخضراء تواجه الكثير من الصعوبات في تحسين مستوى مخرجاته حيث زادت التعقيدات التي ترتبط 
بتصميم المباني الحديثة، وباتت أكثر تعقيداً عند تصميم المباني الخضراء الأمر الذي تتطلب أكثر معرفة ودراية بسبل تطبيق متطلبات الاستدامة وما تحتاجه من مهارات. وفيما يلي يلقي البحث مزيداً من الضوء على خصائص فريق التصميم ومناقشتها.

\section{مستوى خبرة فريق التصميم وأثره على مخرجات التصميم المستدام}

أظهرت نتائج الدراسة كما بالجدول رقم (2) أن مستوى خبرة فريق التصميم كان متدنياً (2.55). هذه

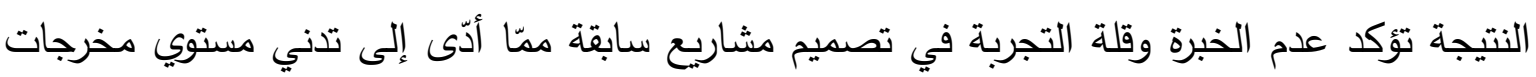

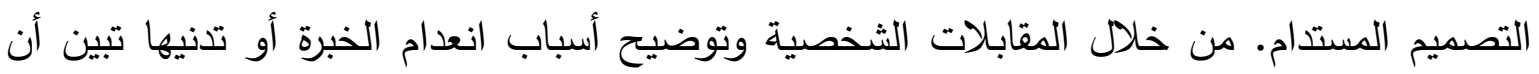

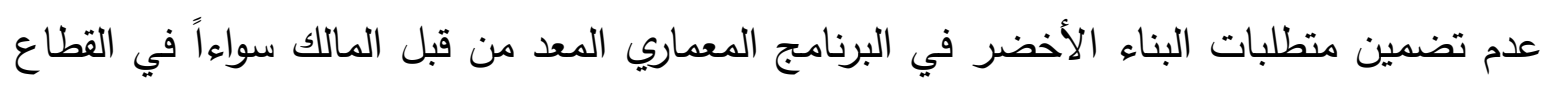
العام أو الخاص أحد أسباب انعدام الخبرة أو تدنيها لدي فرق التصني التصمين.

الجدول (2): مستوى خبرة فريق التصميم

\begin{tabular}{|c|c|c|}
\hline 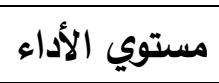 & الوسيط & مفردات خبرة فريق التصميم \\
\hline 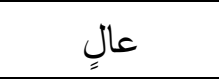 & 3.92 & مدي خبرة فريق التصميم في مجال المرافق والمباني التقليدية \\
\hline متدنٍ جدا & 1.17 & مدي خبرة فريق التصميم في مشاريع سابقة مستدامة \\
\hline متدنِّ & 2.55 & مستوى الأداء العام \\
\hline
\end{tabular}

أغلب فرق التصميم تفتقر لوجود الخبرة والتجربة الكافية التي تمكنها من المخاطرة بتبني فكرة تصميم

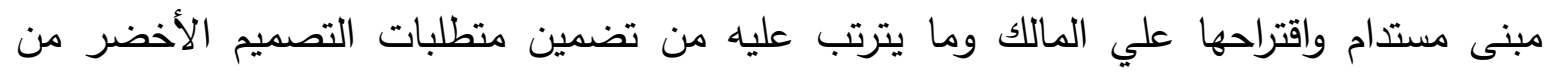

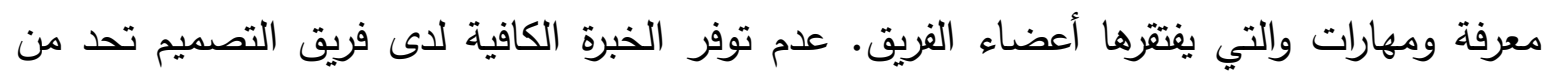

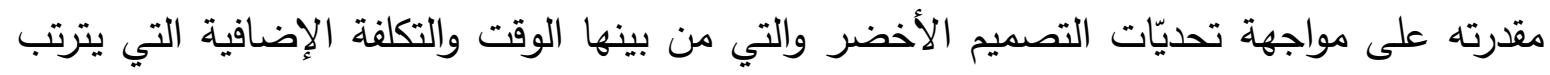
عليها أعمال التصميم الأخضر التي لم ترد بالبرنامج المعماري المعد من المالك والذي من خلاتلاتله يتم

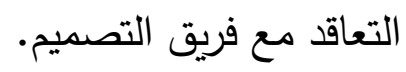

لكي يتجاوز فريق التصميم عقبة قصور الخبرة يتوجب عليه زيادة حجم المعرفة بمنطلبات التصميم الأخضر والانخراط في برامج التدريب التي تتعلق برفع كفاءة استهلاك الطاقة والمياه والبيئة الداخلية

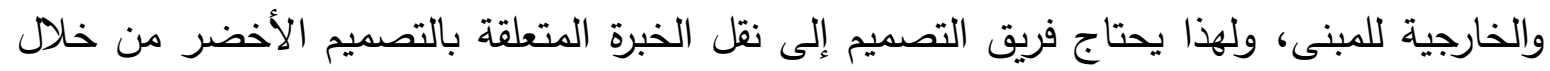
الانخراط في المشاركة مع بيوت الخبرة التي لها تجارب واسعة في هذا لهات المجال. فاعلية إدارة عمليات التصميم تعدّ فاعلية إدارة العملية التصميمية من الخصائص العامة الهامة التي يعتمد عليها فريق التصميم في

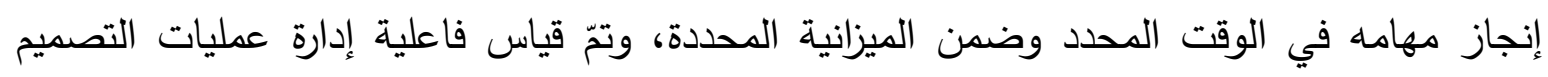


بأربع متغيرات تتعلق بتحديد مستوى القيادة بالفريق أثناء عمليات التصميم، ومدى فاعلية اتخاذ القرار،

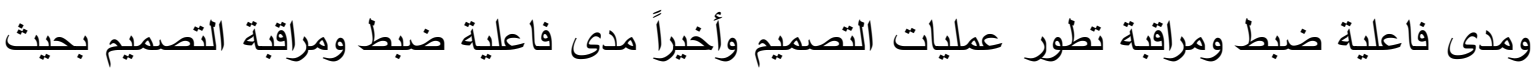

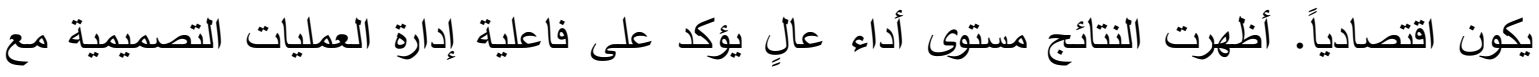
معدل أقل (متوسط 2.92) في مستوى ضبط ومراقبة التصميم بحيث يكون اقتصادياً.

\begin{tabular}{|c|c|c|}
\hline مستوي الأداء & الوسيط & مفردات فاعلية إدارة عمليات التصميم \\
\hline عالٍ & 3.49 & مدى فاعلية القيادة في الفريق أثناء عمليات التصميم \\
\hline عالٍ & 3.52 & مدى فاعلية اتخاذ القرار أثناء عمليات التصميم \\
\hline عالٍ & 3.11 & مدى فاعلية ضبط ومراقبة تطور عمليات التصميم \\
\hline متوسط & 2.92 & مدى فاعلية ضبط ومراقبة التصميم بحيث يكون اقتصادياً \\
\hline عالٍ & 3.26 & مستوى الأداء العام \\
\hline
\end{tabular}

إن ارتفاع مستوى أداء الفريق في إدارة العمليات التصميمية متوقعاً وخصوصاً في بيوت الخبرة التي تختص بمجال التصميم والاستشارات الهندية؛ حيث إنها تضم نخبة من الكفاءات المتخصصة. بينما كان تدني الخصائص المستدامة غير مقبولاً ويعزى ذلك لعدم توفر الإرادة والوعي والالتزام بأهمية

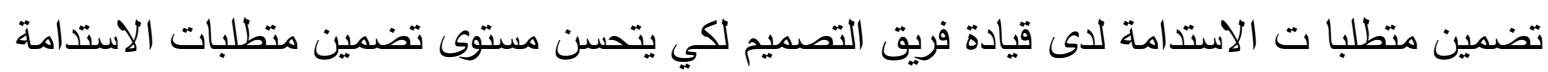

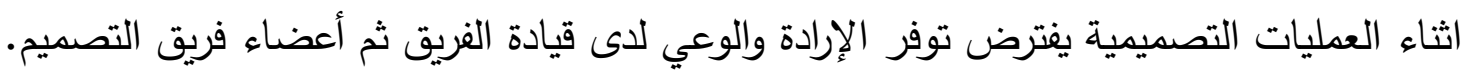
فاعلية التواصل وإدارة المهام

من خصائص فريق التصميم الناجح اعتماد نظام تواصل فعّال وتوزيع واضح للمهام وسرعة حل الاختلافات بين أعضائه؛ حيث يعتمد نجاح فريق التصميم بشكل كبير على فاعلية أسلوب التواصل

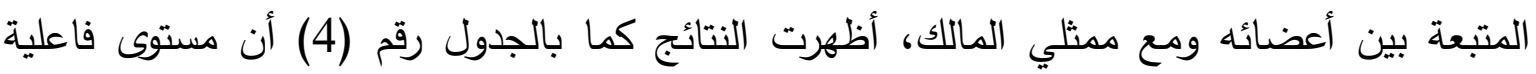

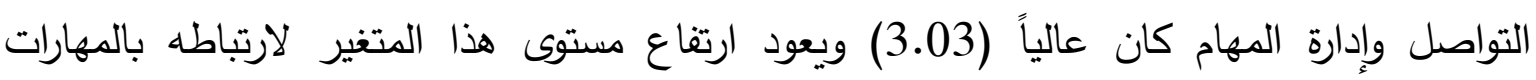
الإدارية وتقدم تقنيات الاتصالات وفاعليتها. 
الجدول (4): فاعلية نظام التواصل وإدارة المهام

\begin{tabular}{|c|c|c|}
\hline 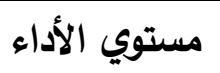 & الوسيط & مفردات نظام التواصل وادارة المهام \\
\hline متوسط & 2.92 & التصميم فاعلية الاتصال والتواصل بين أعضاء الفريق أثناء عمليات \\
\hline 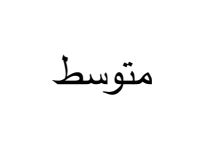 & 2.83 & فمليات التصمية فريق التصميم في حل أية اختلافات بين أعضائه أثناء \\
\hline عالٍ & 3.34 & مدي وضوح واجبات والتزامات كل عضو داخل فريق التصميم \\
\hline عالٍ & 3.03 & مستوى الاداء العام \\
\hline
\end{tabular}

تتسم عمليات التصميم الأخضر بالتعقيد حيث ينخرط أثناءها العديد من الأعضاء بمختلف التفاء التخصصات وللوصول للقرارات التصميمية المناسبة يضطر اعضاء الفريق للتواصل فيما بينهم لاتخاذ القرار المناسب. لذلك لكي يتم فهم وجهات النظر وتفادي سوء فهم الأفكار المطروحة للحلول التصميمية أثناء عمليات التصميم يجب اعتماد سبل تواصل فعالة بحيث تكون في متناول كافة أعضاء الفريق وسهلة الفهم والاستعمال.

من خلال المقابلات الشخصية تبيّن أن معظم فرق التصميم تعتمد في التواصل فيما بينها على شبكة الانترنت واستخدام البرامج الاككترونية المختلفة التي لا تتسم بالتعقيد في التحميل والإرسال والاستقبال.

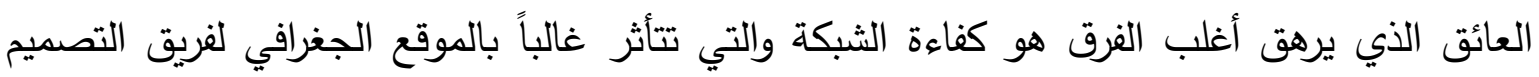

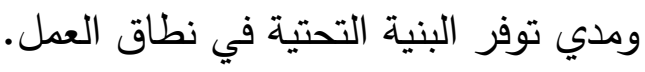

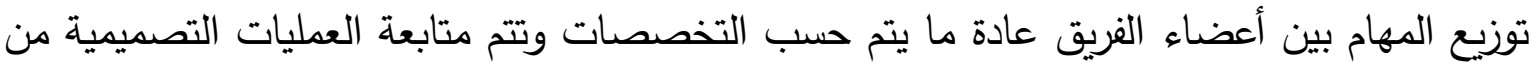

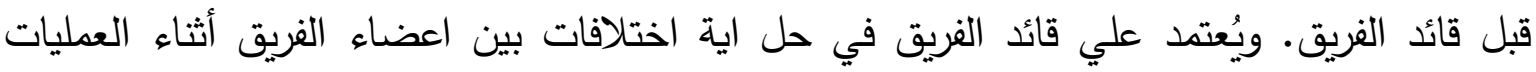

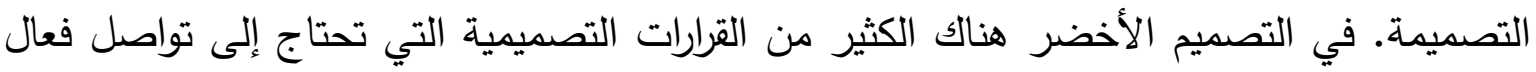
بين أعضاء الفريق في مختلف التخصصات؛ فمثلاً للرفع من كفاءة استهلاك الطاقة يتطلب التعاون

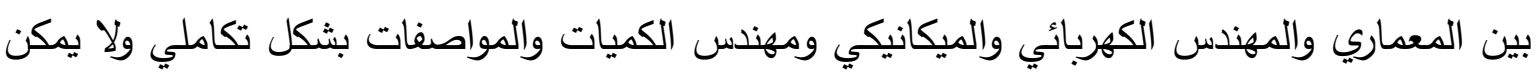

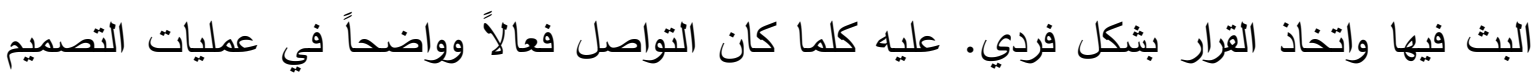
الأخضر كلما زادت فرص تحسن مستوى كفاءة مخرجات التصميم. مستوى المعرفة بالتصميم الأخضر إنّ مستوى المعرفة بالتصميم الأخضر يلعب دوراً جوهرياً في تحسين مخرجات التصميم الأخضر لاسيما العديد من القرارات التصميمية تحتاج إلى خلفية علمية ترتبط بالعلوم البيئية والتقنية 
والاقتصادية. أظهرت النتائج كما بالجدول رقم (5) تدني المستوى العام لمتغير المعرفة بالبناء الأخضر (1.91). بينما بينت النتائج أن أغلب فرق التصميم ليست لها المعرفة الكافية بسبل تقييم الأثر البيئي ومستوى الاستدامة للوصول لتصميم أخضر وبمعدل متدنّ جداً (1.25). الجدول (5): مستوى معرفة فريق التصميم بمتطلبات التصميم المستدام

\begin{tabular}{|c|c|c|}
\hline مستوي الأداء & الوسيط & مفردات المعرفة بالتصميم المستدام \\
\hline متدنّ جدا & 1.25 & معرفة الفريق بأدوات حساب تقييم التصميم المستدام \\
\hline 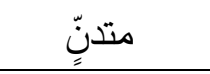 & 2.56 & معرفة الفريق المرتبطة بتصميم المباني المستدامة \\
\hline 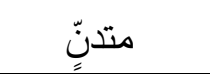 & 1.91 & مستوي الاداء العام \\
\hline
\end{tabular}

كلما زادت درجة المعرفة بمتطلبات البناء الأخضر لاى أعضاء فريق التصميم كلما كانت لهم القدرة

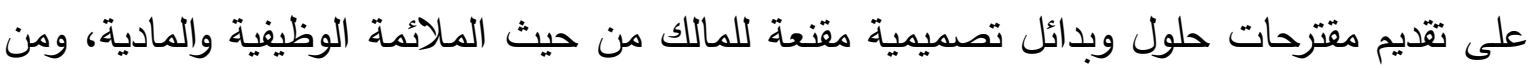

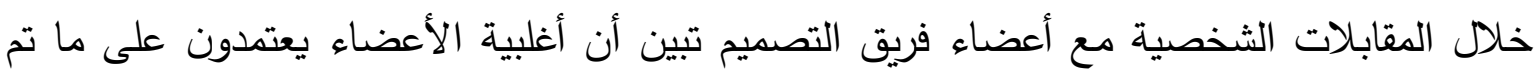

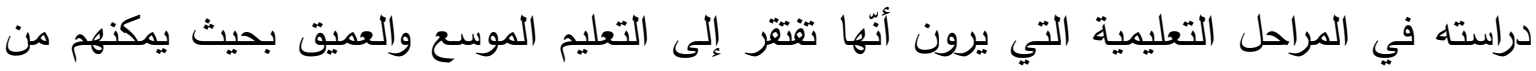
الاستفادة منها في اتخاذ القرارات التصميمية الخضراء. يرى كثير من المهندسين المعماريين أنه بالرغم

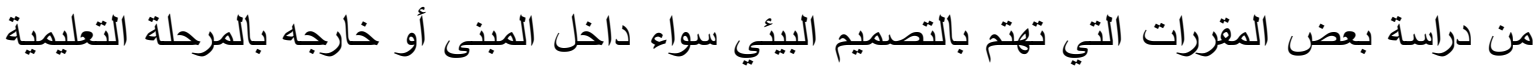

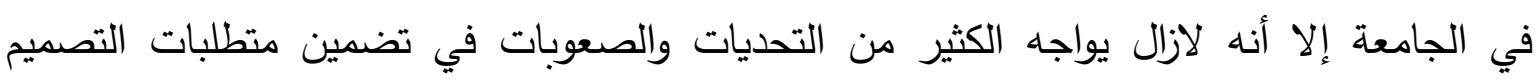
الأخضر وخاصة المتعلقة بالحسابات والبرامج الحاسوبية.

غالباُ مقترحات التصميم الأخضر ما يترتب عليها تكلفة إضافية للمشروع وهنا يعتمد على مدى معرفة

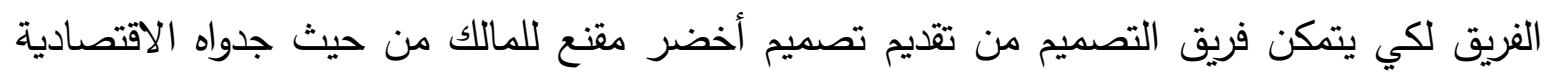

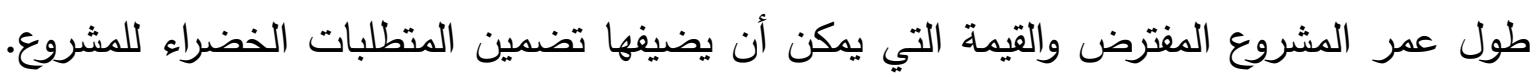

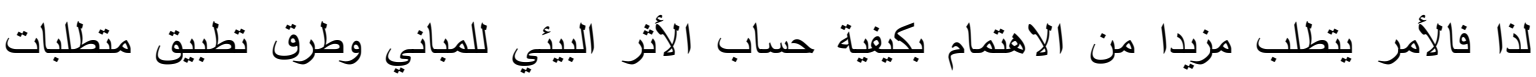
الاستدامة في المباني خلال المراحل التعليمية.

مستوى مهارات فريق التصميم

مستوى مهارات فريق التصميم تعكس مدى قدرة الفريق على تضمين منطلبات الاستدامة بشكل صحيح وفعال، وبيّتت الدراسة كما هو موضح بالجدول (6) أنّ مستوى المهارات بشكل عام متدنِ وأنّ غالبية

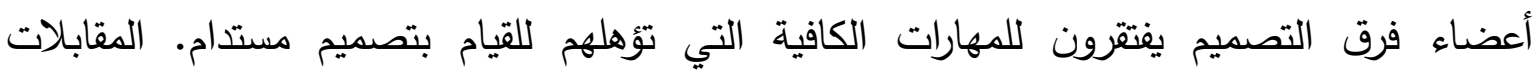

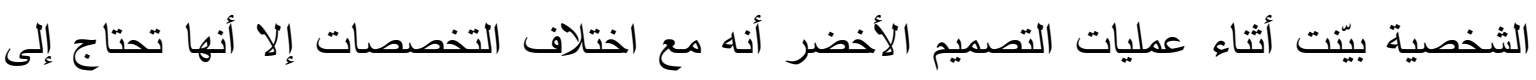


التكامل فيما بينها لاتخاذ القرارات التصميمية المناسبة وأنه لا يمكن الوصول إلى مستوى مقبول

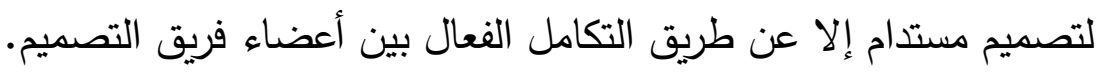

الجدول (6): مستوى مهارات فريق التصميم

\begin{tabular}{|c|c|c|}
\hline 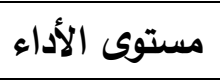 & الوسيط & مفردات مهارات فريق التصميم \\
\hline متدنِ جدا & 144 & المهارات في استخدام برامج الحاسوب في تحقيق التصميم المستدام \\
\hline 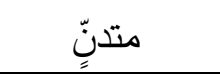 & 1.93 & قدرة فريق التصميم على ترجمة احتياجات المالك في تصميم مستدام فعال \\
\hline متدنِّ جداً & 1.69 & مستوى الأداء العام مان \\
\hline
\end{tabular}

يعاني أغلب أعضاء الفريق من عدم الدراية والخبرة الكافية في تطبيق برامج الحاسوب التي تخص

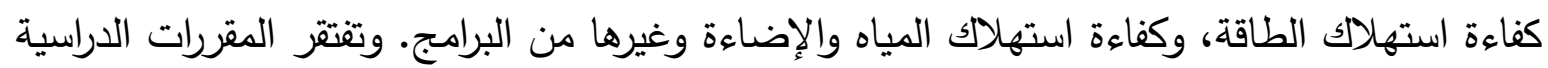

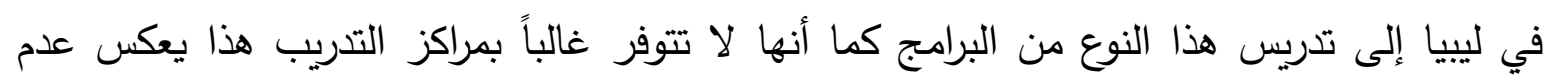

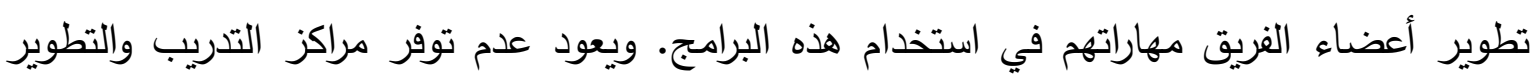

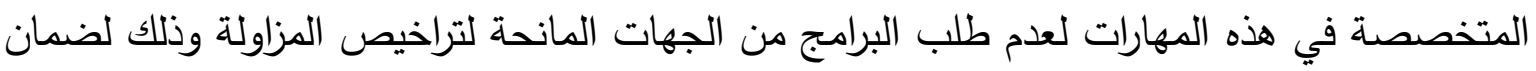
أن المشروع يلبي الحد الأدنى من متطلبات الاستدامة.

عليه للرفع من مستوى مهارات الفريق يتطلب الأمر تضمينها في المناهج الدراسية والتتريبية التي تهتم بالمهارات التصميمية الخضراء. كذلك مزيدا من الوعي لاى المالك يدفع بفريق التصميم للسعي وراء

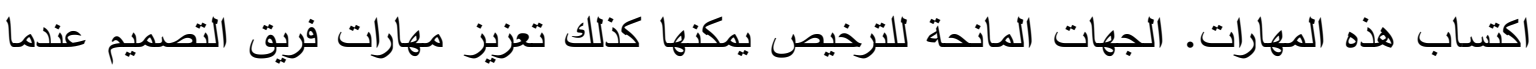
تطلب استخدام هذه الأنواع من البرامج عند اتخاذ القرارات التصميمية المتعلقة بالمباني الخضراء. قدرة فريق التصميم على إنجاز العمل

تعتبر القدرة على إنجاز أعمال التصميم في الوقت المحدد أحد الخصائص التي يقاس بها مستوى

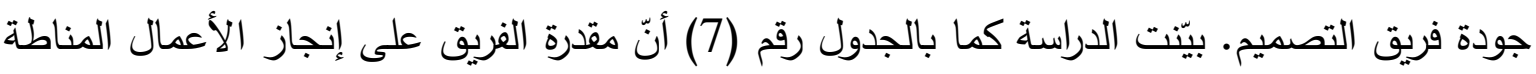

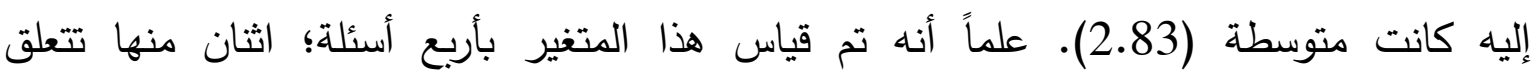

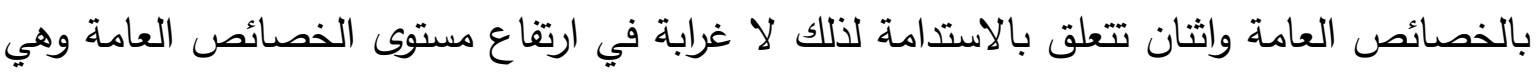

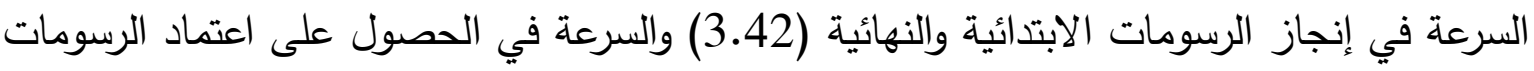

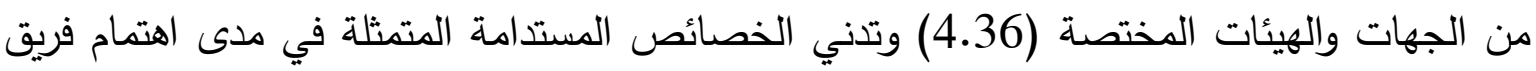
التصميم بالعمل في تصاميم تحقق الاستدامة (1.85) ومقدرة فريق التصميم على التغلب على التى الصعوبات التي تصاحب التصميم المستدام (1.67). 
الجدول (7): يوضح مستوى قدرة الفريق على إنجاز الأعمال التصميمية

\begin{tabular}{|c|c|c|}
\hline 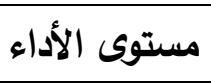 & الوسيط & مفردات قدرة الفريق على إنجاز الأعمال التصميمية \\
\hline عالٍ & 3.42 & السرعة في انجاز الرسومات الابتدائية والنهائية \\
\hline 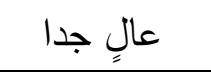 & 4.36 & السرعة في الحصول على اعتماد الرسومات من الجهات والهيئات الدختصة \\
\hline 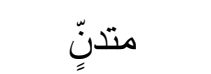 & 1.85 & مدى اهتمام فريق التصميم بالعمل في تصاميم تحقق الاستدامة \\
\hline 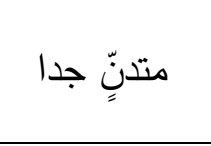 & 1.67 & المستدام فريق التصميم على التغلب على الصعوبات التي تصاحب التصميم \\
\hline متوسط & 2.83 & مستوى الأداء العام \\
\hline
\end{tabular}

إمكانية إنجاز الأعمال التصميمية التقليدية تعتبر في متتاول فريق التصميم رغم التعقيدات المصاحبة

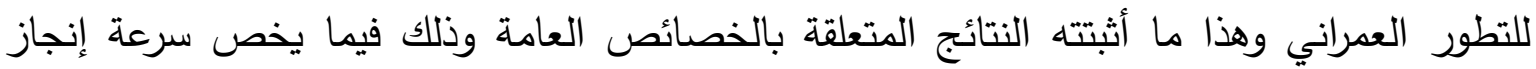

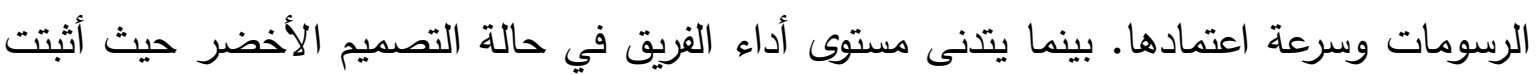

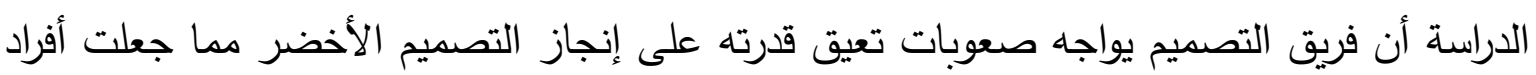

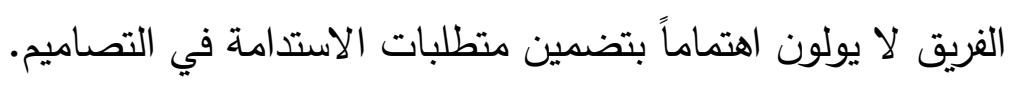

إنّ السرعة في إنجاز الرسومات تعود لفاعلية توزيع المهام والجداول الزمنية لإنجازها. وسرعة اعتمادها

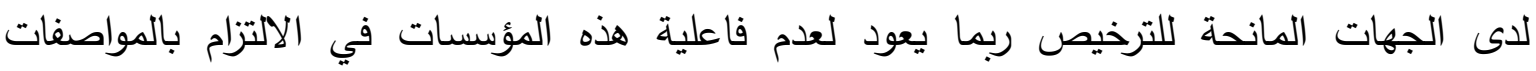

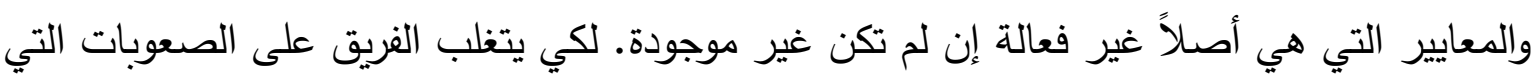

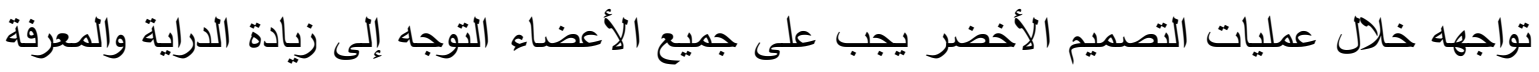

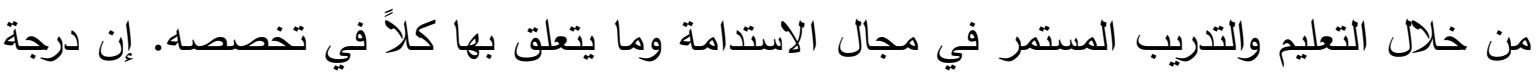
وعي والتزام المالك بأهمية الاستدامة ربما تجعله يطالب بتضمين الاستدامة في البرنامج المعماري (موجز المالك) وكذلك متابعته من قبل ممثليه أثناء عمليات التصميم. كذلك في وجود أنظمة وقوانين فعالة تفرض على كلاً من المالك وفريق التصميم الاهتمام أكثر بتضمين متطلبات الاستدامة في المباني ليست في مرحلة التصميم فقط وإنما في جميع مراحل المشروع.

\section{مستوى الالتزام بالاستدامة}

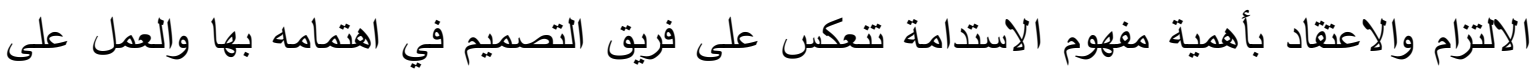

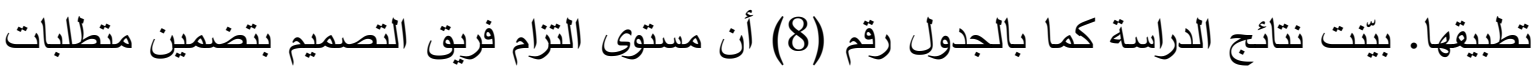

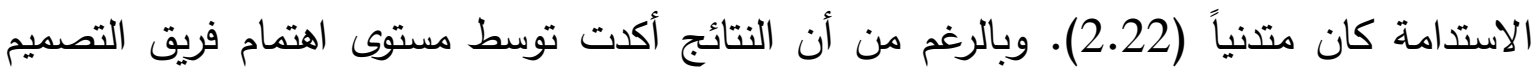
بالاستدامة من خلال تقديمه لمقترحات تدعم تضمين متطلبات الاستدامة إلا أن مستوى الالتزام بتطبيق هذه المقترحات من قبل أعضاء فريق التصميم كانت متدنية. حيث بيّتت النتائج أن درجة الالتزام 
بتضمين متطلبات الاستدامة لكل من المعماري (2.92) والمهندس الكهربائي والميكانيكي (1.91) ومهندس الكميات والمواصفات (1.62).

الجدول (8): يوضح مستوى درجة التزام فريق التصميم بتضمين متطلبات الاستدامة

\begin{tabular}{|c|c|c|}
\hline 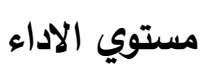 & الوسيط & مستوى درجة التزام الفريق \\
\hline 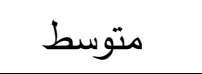 & 2.92 & قدرة الفريق على تقديم المقترحات التي تدعم تحقيق التصميم الدستدام \\
\hline 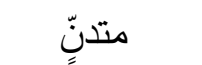 & 1.92 & درجة التزام المهندس المعماري لتحقيق التصميم المستدام \\
\hline 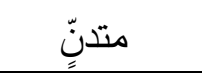 & 1.91 & درجة التزام المهندس الميكانيكي والكهربائي في تحقيق التصميم المستدام \\
\hline 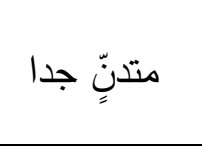 & 1.62 & درالمنتجات الهتمام المهندس المعد للكميات والمواصفات في اختيار المواد \\
\hline 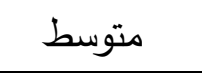 & 2.73 & مدى اهتمام فريق التصميم بتفاصيل التصميم والتنفيذ المستدام \\
\hline 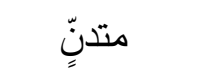 & 2.22 & مستوى الأداء العام \\
\hline
\end{tabular}

النتائج تعكس رغبة فريق التصميم في تضمين متطلبات الاستدامة رغم تفاوت مستوياتها من خلال

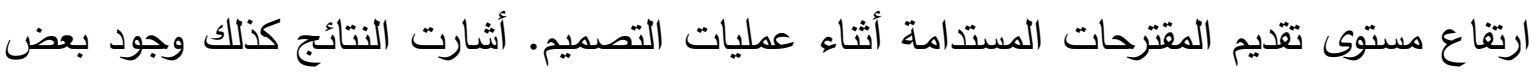

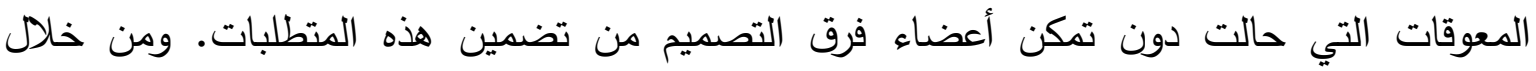

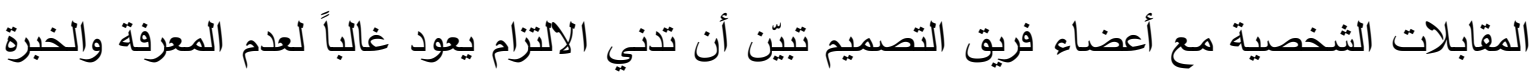

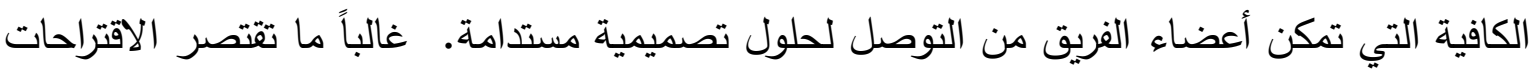

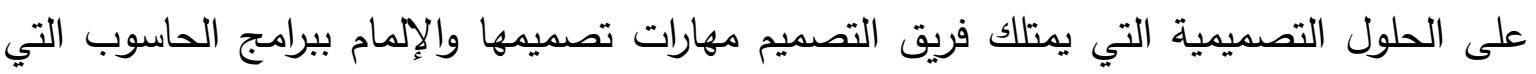
تتعلق بحساباتها مثل استهلالك الطاقة أو كفاءة استهلاك المياه أو التهوية والإضاءة الطبيعية وغيرها. في ضوء رغبة أعضاء فريق التصميم تضمين منطلبات الاستدامة سواءاً كانت بناء على التزام ذاتي

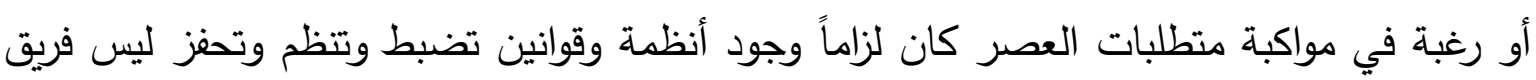
التصميم فحسب بل كل الأطراف الداخلة في كل مراحل المشروع المختلفة بدءاً من المالك وانتهاءاً

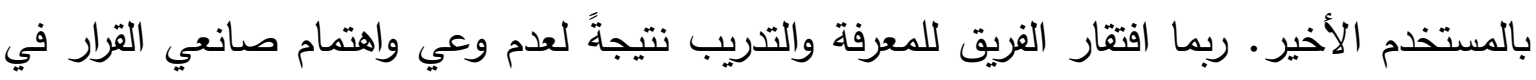

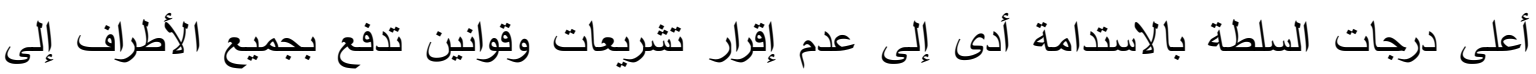

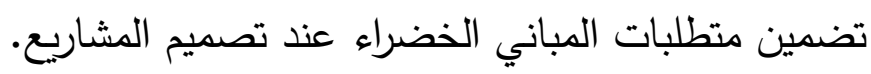


التحديات والصعوبات التي تواجه فريق التصميم

من خلال استعراض النتائج ومناقشتها تبيّن أن تدني مستوى أداء فريق التصميم للمباني الخضراء يعود لعدة تحديات تواجه فريق التصميم، بعض من هذه التحديات داخلية في متتاول الفريق وعليه العمل على تجاوزها وأخري خارجية على الأطراف المعنية تذليلها. فيما يخص العوامل الداخلية يمكن تلخيصها في النقاط التالية:

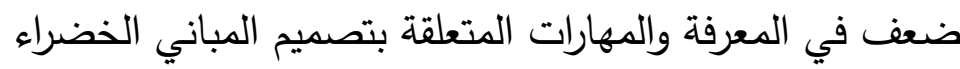
ضعف الوعي والإحساس بالمسئولية الذي ترتب عليه ضعف وات في درجة الالتزام بتضمين منطلبات الاستدامة عند تصميم المباني الخضراء في ليييا. كما يمكن استتتاج العوامل الخارجية في النقاط التالية:

غياب أو عدم فاعلية الأنظمة والتشريعات المنظمة والموجهة لتضمين منطلبات البناء الأخضر لكل الأطراف ذات العلاقة. غياب أو عدم فاعلية المؤسسات المانحة للتراخيص والمؤسسات الرقابية التي تحث وتضبط

$$
\text { تضمين متطلبات الاستدامة في المباني }
$$

عدم وجود نظام تقييم للاستدامة معتمد بالدولة الليبية والذي يجب الذب على فرق التصميم اتباعه.

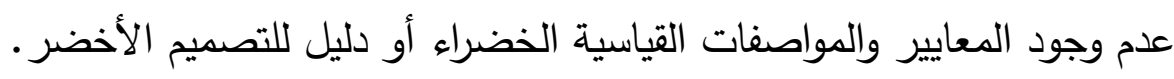

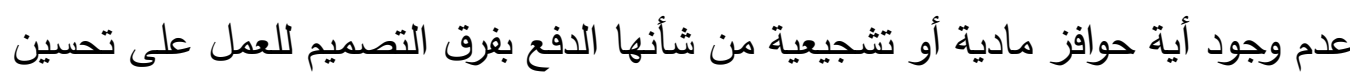
مخرجات التصميم المستدام. الخلاصة والتوصيات

بيّنت الدراسة أن مستوى خصائص فريق التصميم عند تصميم المباني الخضراء كان في مجمله متدنياً

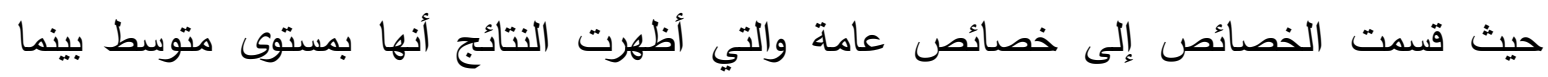
الخصائص التي تتعلق بالاستدامة كانت بمستوى متدنّ.

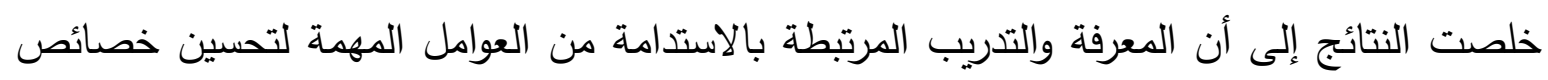

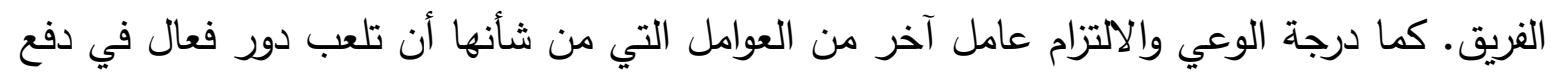
أعضاء فريق التصميم لتبني تضمين متطلبات الاستدامة.

كما انتهات الدراسة بمجموعة من التوصيات أهمها:

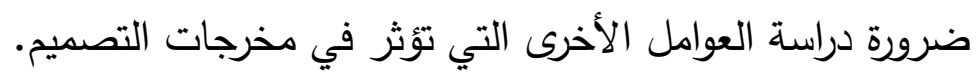

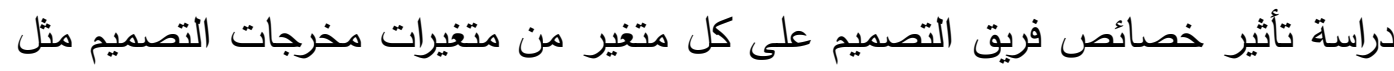
كفاءة الطاقة، كفاءة استهلاك المياه وجودة البيئة الداخلية. الخ. 
التعليم والتدريب المستمر لتحسين خصائص فريق التصميم. كما توصي الدراسة بتضمين مقررات دراسية عن الاستدامة في المناهج التعليمية في الجامعات والمعاهد العليا.

ضرورة إنشاء مراكز تدريب للمهندسين والفنيين للرفع من كفاءتهم ومهاراتهم المهنية في

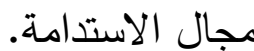

إنشاء جسم يعنى بتقييم الأثر البيئي للمباني ونظام تقييم الاستدامة في مراحل المشروع المختلفة إصدار دليل وكود التصميم الأخضر أسوةً بالدول الأخرى. تكثيف الحملات التوعوية بمفهوم الاستدامة وأهميتها. العمل من خلال القنوات التشريعية والتنفيذية على إصدار القوانين والأنظمة واللوائح والمعايير والمواصفات الفنية التي تساهم في تحسين مخرجات التصميم الأخضر .

- AUBE, C. \& ROUSSEAU, V. 2005. Team Goal Commitment and Team Effectiveness: The Role of Task Interdependence and Supportive Behaviors. Group Dynamics: Theory, Research, and Practice, 9, 189-204.

- DANIELLE, M. 2007. Design and sustainable commercial buildings. Available:http://www.yourbuilding.org/Article/NewsDetail.aspx?p=83\&id=157 1 [Accessed 03 -02- 2011].

- DODGE DATA ANALYSIS REPORT 2018. World Green Building Trends 2018 In: A.JONES, S. (ed.) Design and construcyin intelliglence Green building Councl.

- EKHLAT, M., IBRAHIM M. SALAH \& NURREDIN M. KREAMA 2007. Energy Efficiency and Renewable Energy Libya. National study in Mediterranean and National Strategies for Sustainable Development Priority Field of Action, 51.

- ELFORGANI, M. S. \& RAHMAT, I. 2010. An Investigation of Factors Influencing Design Team Attributes in Green Buildings. American Journal of Applied Sciences 7, 963-973.

- ElForgANI, M. S. \& RAHMAT, I. 2012. The Influence of Design Team Attributes on Green Design Performance of Building Projects. Environmental Management and Sustainable Development, 1, 10-30.

- EMMITT, S. 2010. Design Management In Architecture, Engineering And Construction: Origins And Trends. Gestao \& Tecnologia de Projetos, 5. 
- FORGUES, D. \& LAURI, K. 2008. Can Procurement Affect Design Performance? Journal of Construction Procurement, 14, 130 -141.

- GILlEy, J. J. W., WAiTE, A. M. \& VELIQUETTE, A. 2010. Integrated Theoretical Model for Building Effective Teams. Advances in Developing Human Resources, 12, 7 -28.

- GRAHAM, P. 2003. The Role Of Environmental Performance Assessment In Australian Building Design. The Future of Sustainable Construction.

- HARPUTlugil, G. U. 2009. An Assessement Model Addressed To Early Phases Of Architectural Design Process Prioritised By Energy Performance Ph.D Degree, Gazi University.

- J. ZUO, L. DANIEL \& V. SOEBARTO (EDS.) 2016. Fifty years later: Revisiting the role of architectural science in design and practice. 50th International Conference of the Architectural Science Association 2016. The Architectural Science Association and The University of Adelaide.2016.

- JAFFE, D. T. 2003. Creating effective management teams. Families in Business.

- JAYASEL, R. P. 2006. Development Of Civil And Structural Consultant's Performance Evaluation. Master of Science Universiti Teknologi Malaysia.

- LANTZ, A. \& KIN, A. 2009. Personal initiative at work and when facing unemployment. Journal of Workplace Learning, 21, 88 -108.

- MEGAT, A. A. 2006. The Limitations and Opportunities to Implement Environmental Management System in Malaysia. Jurnal Alam Bina.

- NEWELL, G. 2008. The strategic significance of environmental sustainability by Australian-listed property trusts. Journal of Property Investment \& Finance, $26,522-540$.

- NEWTON, A. 2008. What is effective Design Management? Adept Management Ltd.

- PUTTE, I. V. D. 2007. Project Sustainability Management - beyond the greening of buildings. Conference on Sustainable Building South-East Asia (SB07SEA) KualaLumpur,Malaysia.

- REED, R., BILOS, A., WILKINSON, S. \& SCHULTE, K. 2009. International Comparison of Sustainable Rating Tools. Journal of Sustainable Real Estate, 122. 
- S. K. ALGHOUL \& HATAB, A. M. 2016. Building Energy Efficiency: Optimization of Building Envelope Using Grey-Based Taguchi. Journal of Multidisciplinary Engineering Science and Technology, 3, 6192-6197.

- SHAFII, F., ALI, Z. A. \& OTHMAN, M. Z. Achieving Sustainable Construction In The Developing Countries Of South East Asia the 6th AsiaPacific Structural Engineering and Construction Conference, 5 - 6 September 20062006 Kuala Lumpur, Malaysia. 29 - 44.

- SHARI, Z., ZAKY, J. M. F., SALLEH, E. \& HAW, L. C. 2008. The Potential of Sustainable Building Rating System in the Malaysian Building Industry. International Journal on Sustainable Tropical Design Research \& Practice, 3, 3 14.

- SHIRAZI, A. \& MORTAZAVI, S. 2009. Effective Management Performance A Competency-Based Perspective. International Review of Business Research Papers, 5, 1 - 10. 